\title{
Transplantation of a kidney with a heterozygous mutation in the SLC22A12 (URAT1) gene causing renal hypouricemia: a case report
}

\author{
Kiyokazu Tsuji1, Mineaki Kitamura ${ }^{1 *}$ (D), Kumiko Muta ${ }^{1}$, Yasushi Mochizuki ${ }^{2}$, Takayasu Mori ${ }^{3}$, Eisei Sohara ${ }^{3}$,
} Shinichi Uchida ${ }^{3}$,Hideki Sakai ${ }^{2}$, Hiroshi Mukae ${ }^{4}$ and Tomoya Nishino ${ }^{1}$

\begin{abstract}
Background: Renal hypouricemia (RHUC) is a genetic disorder caused by mutations in the SLC22A12 gene, which encodes the major uric acid (UA) transporter, URAT1. The clinical course of related, living donor-derived RHUC in patients undergoing kidney transplantation is poorly understood. Here, we report a case of kidney transplantation from a living relative who had an SLC22A12 mutation. After the transplantation, the recipient's fractional excretion of UA (FEUA) decreased, and chimeric tubular epithelium was observed.

Case presentation: A 40-year-old man underwent kidney transplantation. His sister was the kidney donor. Three weeks after the transplantation, he had low serum-UA, $148.7 \mu \mathrm{mol} / \mathrm{L}$, and elevated FEUA, 20.8\% (normal: < 10\%). The patient's sister had low serum-UA (101.1 $\mu \mathrm{mol} / \mathrm{L})$ and high FEUA (15.8\%) before transplant. Suspecting RHUC, we performed next-generation sequencing on a gene panel containing RHUC-associated genes. A heterozygous missense mutation in the SLC22A12 gene was detected in the donor, but not in the recipient. The recipient's serum-UA level increased from $148.7 \mu \mathrm{mol} / \mathrm{L}$ to $231.9 \mu \mathrm{mol} / \mathrm{L} 3$ months after transplantation and was $226.0 \mu \mathrm{mol} / \mathrm{L}$ 1 year after transplantation. His FEUA decreased from 20.8 to $11.7 \% 3$ months after transplantation and was $12.4 \% 1$ year after transplantation. Fluorescence in situ hybridization of allograft biopsies performed 3 months and 1 year after transplantation showed the presence of $Y$ chromosomes in the tubular epithelial cells, suggesting the recipient's elevated serum-UA levels were owing to a chimeric tubular epithelium.
\end{abstract}

Conclusions: We reported on a kidney transplant recipient that developed RHUC owing to his donor possessing a heterozygous mutation in the SLC22A12 (URAT1) gene. Despite this mutation, the clinical course was not problematic. Thus, the presence of donor-recipient chimerism in the tubular epithelium might positively affect the clinical course, at least in the short-term.

Keywords: SLC22A12, Renal hypouricemia, Chimerism, Renal allografts, Fluorescence in situ hybridization

\footnotetext{
* Correspondence: mkitamura-ngs@umin.ac.jp

'Department of Nephrology, Nagasaki University Graduate School of Biomedical Sciences, Nagasaki, Japan

Full list of author information is available at the end of the article
}

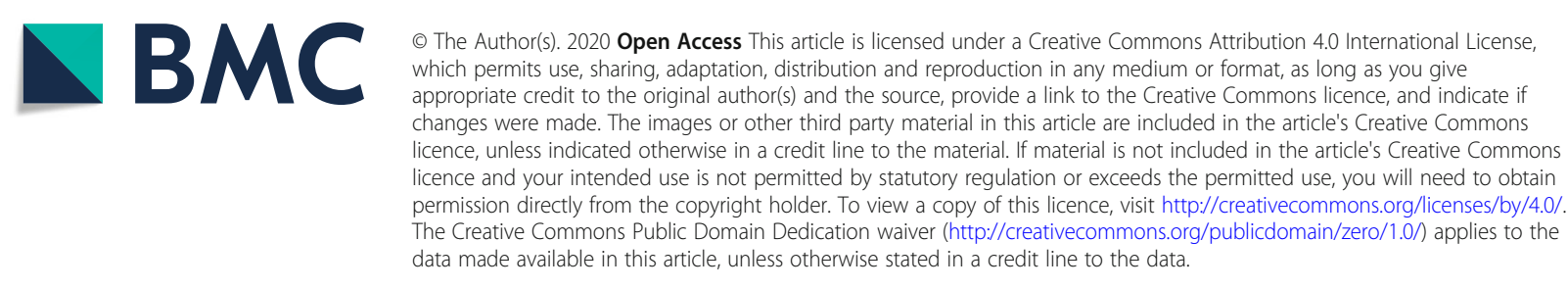




\section{Background}

Renal hypouricemia (RHUC) is a genetic disorder caused by a defect in the urate transporter 1 (URAT1) protein, often causing urolithiasis and exercise-induced acute renal failure [1-5]. URAT1 is responsible for uric acid (UA) reabsorption at the brush border membrane of the renal proximal tubules and is encoded by the $S L C 22 A 12$ gene $[4,5]$. In addition, a heterozygous missense mutation in SLC22A12 can cause RHUC [6].

At present, two reports showed successful kidney transplantation from living, related donors and recipients affected with hereditary RHUC [7, 8]. However, whether the RHUC donor affects the outcome of the recipient remains unknown. Therefore, the clinical course of these cases should be carefully evaluated. The role of chimeric cells in graft adaptation has long been the subject of transplantation research. The occurrence of sex chromosome chimerism, particularly Y chromosome chimerism, is commonly observed in sex-mismatched kidney transplants through renal allografts performed 1 year or more post-transplant [9]. The presence of $\mathrm{Y}$ chromosomal tubular chimerism is generally detected with fluorescence in situ hybridization (FISH) or chromogenic in situ hybridization methods [9].

We reported on a case of donor-derived RHUC in a kidney recipient, focusing on the detection of Y chromosome chimerism in the tubular epithelium of the recipient using FISH.

\section{Case presentation}

The recipient was a 40-year-old Japanese man that was diagnosed with proteinuria during a previous medical examination at 28 years of age. However, he did not receive any form of treatment for this condition and had not received any kind of medical care until 38 years of age, when he sought treatment for severe fatigue and anorexia. Laboratory tests showed a serum creatinine (S$\mathrm{Cr}$ ) level of $1113.8 \mu \mathrm{mol} / \mathrm{L}$ and serum-UA (S-UA) level of $743.5 \mu \mathrm{mol} / \mathrm{L}$. He was referred to the nephrology department of another hospital to receive hemodialysis. The etiology of his renal failure was unknown because a renal biopsy was not performed.

Two years later, he underwent kidney transplantation. The patient's donor was his living sister, and the clinical course after transplantation was uneventful. Three weeks after kidney transplantation, his S-Cr was $100.7 \mu \mathrm{mol} / \mathrm{L}$, and he had a slightly low S-UA $(148.7 \mu \mathrm{mol} / \mathrm{L}$; normal: $220-463.9 \mu \mathrm{mol} / \mathrm{L}$ ) with a fractional excretion of UA (FEUA) of $20.8 \%$ (normal: $<10 \%$ ). A physical examination of the patient did not reveal any abnormalities.

The donor was the patient's 42-year-old sister. Before donation, her S-UA and FEUA levels were $101.1 \mu \mathrm{mol} / \mathrm{L}$ and $15.8 \%$, respectively. Other clinical data were normal (Table 1). There was no history of kidney stones, acute
Table 1 Laboratory data of the donor, before kidney transplantation

\begin{tabular}{|c|c|c|}
\hline \multirow{2}{*}{ Complete blood cell coun } & \multicolumn{2}{|c|}{ Normal ranges for female } \\
\hline & & \\
\hline WBC $\left(\times 10^{9}\right.$ cells $\left./ \mathrm{L}\right)$ & $3.3-8.6$ & 4.5 \\
\hline RBC $\left(\times 10^{12}\right.$ cells $\left./ L\right)$ & $3.86-4.92$ & 4.47 \\
\hline Hemoglobin (g/L) & $116-148$ & 108 \\
\hline Hematocrit (\%) & $35.1-44.4$ & 34.9 \\
\hline Platelets $\left(\times 10^{9} / \mathrm{L}\right)$ & $158-348$ & 329 \\
\hline \multicolumn{3}{|l|}{ Serum biochemistry } \\
\hline Total protein $(\mathrm{g} / \mathrm{L})$ & $66-81$ & 70 \\
\hline Albumin (g/L) & $41-51$ & 41 \\
\hline $\mathrm{BUN}(\mathrm{mmol} / \mathrm{L})$ & $2.85-7.14$ & 4.28 \\
\hline $\mathrm{Cr}(\mu \mathrm{mol} / \mathrm{L})$ & $40.66-69.83$ & 44.25 \\
\hline Uric acid ( $\mu \mathrm{mol} / \mathrm{L})$ & $154.64-327.14$ & 101.1 \\
\hline Sodium (mmol/L) & $138-145$ & 139 \\
\hline Potassium (mmol/L) & $3.6-4.8$ & 4.2 \\
\hline Chloride (mmol/L) & $101-108$ & 105 \\
\hline Calcium (mmol/L) & $2.19-2.51$ & 2.19 \\
\hline Phosphorous (mmol/L) & $0.87-1.48$ & 0.9 \\
\hline \multicolumn{3}{|l|}{ Urinalysis } \\
\hline $\mathrm{pH}$ & $4.6-7.5$ & 6.0 \\
\hline Specific gravity & $1.006-1.022$ & 1.007 \\
\hline Protein & & $(-)$ \\
\hline Occult blood & & $(-)$ \\
\hline RBC sediment (/HPF) & & $1-4$ \\
\hline WBC sediment (/HPF) & & $1-4$ \\
\hline $\mathrm{CCr}(\mathrm{mL} / \mathrm{min})$ & & 260 \\
\hline Urinary protein excretio & & 50 \\
\hline Urine $\mathrm{Cr}(\mu \mathrm{mol} / \mathrm{L})$ & & 3500.6 \\
\hline Urine uric acid $(\mu \mathrm{mol} / \mathrm{L})$ & & 1266.9 \\
\hline
\end{tabular}

$B U N$ blood urea nitrogen, $\mathrm{Cr}$ creatinine, $\mathrm{CCr}$ creatinine clearance, $\mathrm{RBC}$ red blood cells, WBC white blood cell, (-), not detected

renal failure, and/or hypouricemia. Their father was alive and healthy, and his medical history did not indicate any kidney dysfunction, including urolithiasis and acute renal failure. However, their mother had two episodes of urolithiasis at 19 years of age.

Based on these findings, we suspected that the donor had RHUC. After obtaining the informed consent from both the donor and the recipient, we performed next-generation sequencing with a gene panel containing RHUC-associated genes on both of them, including $S L C 22 A 12$, the most common causative gene of RHUC and SLC2A9 [10]. We found a missense heterozygous $G$ to A substitution in position 269 in the exon 1 (NM_144585.4:c.269G > A (p.Arg90His)) in the donor, but not in the recipient. The American College of Medical Genetics and 
Genomics variant classifications for this variant are shown in Supplemental Material 1 [11].

The recipient had an excellent transplantation outcome: two years after the surgery, he had no major complications, including urolithiasis or exercise-induced acute renal failure. The recipient's S-UA level was 231.9 and $226.0 \mu \mathrm{mol} / \mathrm{L}, 3$ months and 1 year after transplantation, respectively. His S$\mathrm{Cr}$ level did not significantly change from his levels 3 weeks after transplant, and was 96.3 and $93.7 \mu \mathrm{mol} / \mathrm{L}, 3$ months and 1 year after transplantation, respectively. His FEUA decreased from $20.8 \%$ before the surgery, to 11.7 and $12.4 \%, 3$ months and 1 year after transplantation, respectively. Therefore, we hypothesized the presence of donor-recipient chimerism in the tubular epithelium, played a role in the UA reabsorption process. FISH of the allograft biopsies taken 3months and 1-year post-transplantation detected the presence of the Y chromosome in the tubular epithelium. The protocol of FISH is shown in Supplemental Material 2. Among the three biopsies, no evidence of $\mathrm{T}$ cell-mediated rejection, nor structural anomalies of the glomerulus, tubules, interstitium, and vessels were observed. Y chromosome-positive cells were detected mainly in the interstitium and some tubules in the graft. The interstitium typically contains white blood cells; given this, we concluded the Y chromosome-positive cells were white blood cells. Most tubular epithelial cells were of donor origin, but we also found chimeric cells (Fig. 1). After the transplantation, the donor's S-Cr increased to approximately $88.4 \mu \mathrm{mol} / \mathrm{L}$, with an FEUA of approximately $20 \%$. She did not have any complications following the kidney donation.

\section{Discussion and conclusions}

We reported on a kidney transplantation case in which the donated kidney had a heterozygous mutation in the
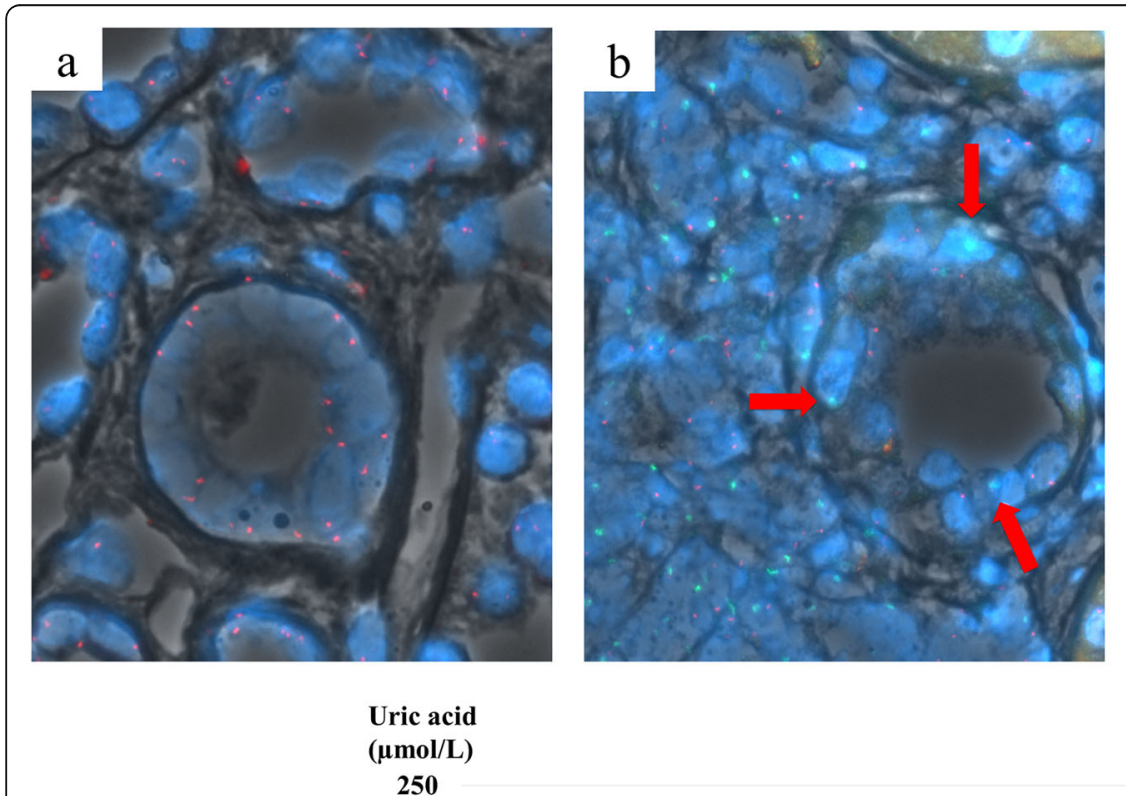

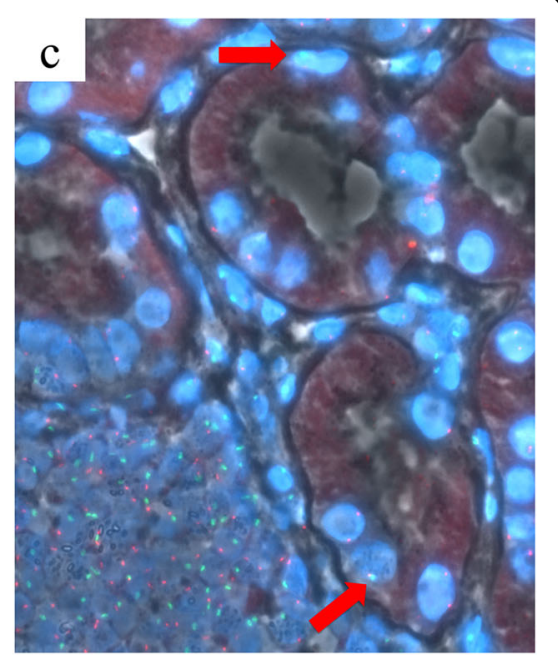

FEUA

(\%)

25

20

15

10

5

0

\section{d 0 week 3 month 1 year}

Fig. 1 a 0-h biopsy; FISH with a probe against X chromosome (red) of the normal tubular epithelium. b, c 3-month protocol biopsy; FISH with probes against the $Y$ chromosome (green) and the $X$ chromosome (red) of the recipient tubular epithelium. Sex chromosomes are indicated with an arrow. d Clinical course; The levels of uric acid increased after transplantation; on the other hand, the fractional excretion of uric acid decreased after transplantation. FEUA: fractional excretion of uric acid 
SLC22A12 (URAT1) gene, known to cause RHUC. As opposed to previously reported kidney transplants where both the donor and recipient had RHUC [7, 8], the recipient in our case did not have RHUC prior to receiving the transplanted kidney. We investigated the recipient's physiological adaptations to receiving a kidney affected by RHUC and whether the recipient would develop RHUC.

According to a previous report, the incidence of hypouricemia, defined as an S-UA of $\leq 118.9 \mu \mathrm{mol} / \mathrm{L}$ $(2.0 \mathrm{mg} / \mathrm{dL})$, in outpatients is $0.16 \%$ in men and $0.24 \%$ in women [12]. In RHUC, urinary excretion of UA increases due to impaired membrane transport of urate in the renal proximal tubules [13]. Thus, mutations in several tubular transporters, including URAT1 and glucose transporter 9 (GLUT9), are associated with RHUC. In patients with RHUC, mutations in the $S L C 22 A 12$ gene, encoding URAT1, were the most frequent $[4,6]$. The donor in our case report had a heterozygous G269A mutation in the SLC22A12 gene. The G269A mutation is causative for RHUC and is the second most prevalent cause of RHUC [14, 15]. The allele frequency of the G269A variant is $7.3,9.1$, and $38.5 \%$ in Japanese, Koreans, and Chinese patients affected with RHUC, respectively [15].

RHUC is typically an autosomal recessive disease, caused by homozygote or compound heterozygous mutations. Moreover, single heterozygous mutations can cause hypouricemia symptoms $[6,16]$. Patients with homozygous URAT1 mutations typically have an S-UA $<59.4 \mu \mathrm{mol} / \mathrm{L}(<1.0 \mathrm{mg} / \mathrm{dL})$, while some patients with heterozygous URAT1 mutations have an S-UA > $118.9 \mu \mathrm{mol} / \mathrm{L}$ ( $>2.0 \mathrm{mg} / \mathrm{dL})$ [17]. In this case, a single heterozygous mutation could cause RHUC, and both our recipient and donor had $\mathrm{S}-\mathrm{UA}>118.9 \mu \mathrm{mol} / \mathrm{L}$. The reason why this case could be diagnosed as RHUC was owing to the donor's status as a premenopausal woman because estrogen can accelerate UA exclusion [18].

Hypouricemia is a risk factor for urolithiasis and exercise-induced acute renal failure [2, 3]. Some patients with exercise-induced acute renal failure require temporary dialysis, and their short-term prognosis is good [2]. Only a few reports described the long-term prognosis of patients with hypouricemia, especially in patients who underwent renal transplantation $[7,8]$. RHUC cases with major complications (exercise-induced acute renal failure and urolithiasis) present with UA levels $<118.9 \mu \mathrm{mol} / \mathrm{L}$ $([2,17,19,20]$. However, a few cases of exerciseinduced acute renal failure have been reported with mild RHUC and with UA levels between 124.9 and $178.4 \mu \mathrm{mol} / \mathrm{L}$ (between 2.1 and $3.0 \mathrm{mg} / \mathrm{dL}$ ) [21, 22].
Following transplantation, the recipient's S-UA level increased (between 124.9 to $178.4 \mu \mathrm{mol} / \mathrm{L}$ ), the FEUA level decreased, and the $\mathrm{S}$-Cr level did not change. The stable S-Cr level, in particular, is a sign of a good outcome. It was important to follow-up with this patient to monitor for potential hypouricemia complications. Moreover, the patient was directed to avoid strenuous exercise, which may lead to exercise-induced acute renal failure, and to drink plenty of water, which will alkalize his urine and help prevent urolithiasis [23, 24].

We speculated that the increase in S-UA and decrease in FEUA levels were owing to an adaptive physiological change after transplantation. In contrast with previous reports in which both the recipient and the donor were affected by RHUC, in our case report, only the donor had the disease [7, 8]. Therefore, we suspected the presence of chimerism in the tubular epithelium. As expected, the allograft biopsies taken 3-months and 1-year posttransplantation and evaluated by FISH showed the presence of cells carrying the $\mathrm{Y}$ chromosome in the tubular epithelium. Sex chromosome chimerism, particularly Y chromosome chimerism, is common in kidney allograft biopsies from sex-mismatched pairs and is detected in approximately $40-70 \%$ of kidney biopsies in both genders performed more than 1year post-transplantation [9]. To the best of our knowledge, this is the first report identifying chimerism in tubular epithelial cells after kidney transplantation from a donor affected by RHUC to a recipient without RHUC. We hypothesize that the serum-UA level in the recipient increased owing to the chimerism of the tubular epithelium.

This case report had an important limitation. Although we speculated that the decrease in FEUA level observed in the recipient was related to tubular chimerism, other factors may have been responsible for this decrease, especially since the ratio of tubular chimerism was very small. We estimated that the ratio was around $10 \%$, but we did not have enough images to perform a semi-quantitative analysis. Moreover, although the clinical course of the recipient was good in the short-term, the recipient and donor have to be monitored very closely, especially for signs of renal failure.

In conclusion, we reported on a kidney transplantation case in which the donor was affected by RHUC due to a heterozygous mutation in the SLC22A12 (URAT1) gene, and the recipient did not develop RHUC owing to the presence of chimerism in the tubular epithelium. Further studies are necessary to predict the clinical outcomes following kidney transplantation for donors and recipients when one or both are affected by RHUC. 


\section{Supplementary information}

Supplementary information accompanies this paper at https://doi.org/10. 1186/s12882-020-01940-4.

Additional file 1: Supplemental Material 1. The American College of Medical Genetics and Genomics variant classifications variant classifications to (NM_144585.4:c.269G > A:p.(Arg90His).

Additional file 2: Supplemental Material 2. FISH protocol.

\section{Abbreviations}

RHUC: Renal hypouricemia; FISH: Fluorescence in situ hybridization;

FEUA: Fractional excretion of uric acid; URAT1: The urate transporter 1

\section{Acknowledgments}

The authors thank Masahisa Tsuji for his invaluable technical assistance and Editage (www.editage.com) for English language editing.

\section{Declarations}

Not applicable.

\section{Authors' contributions}

MK, YM, and HS treated the patient. KT, MK, and KM drafted the manuscript. HS, HM, and TN reviewed the manuscript. KT and MK interpreted the patient's data. TM, ES, and SU performed the genetic analysis. All authors contributed to the preparation of the manuscript and approved the final version.

\section{Funding}

Not applicable.

\section{Availability of data and materials}

Anonymized data can be provided by the corresponding author for a reasonable request.

\section{Ethics approval and consent to participate}

This case report was approved by the Ethical Committee of the Nagasaki University Hospital (20042031).

\section{Consent for publication}

Written informed consent to publish this case report, and any accompanying images were obtained from the donor and the recipient. A copy of the written consent is available for review from the journal's Editor.

\section{Competing interests}

The authors declare no competing interests.

\section{Author details}

${ }^{1}$ Department of Nephrology, Nagasaki University Graduate School of Biomedical Sciences, Nagasaki, Japan. ²Department of Urology, Nagasaki University Graduate School of Biomedical Sciences, Nagasaki, Japan. ${ }^{3}$ Department of Nephrology, Graduate School of Medical and Dental Sciences, Tokyo Medical and Dental University, Tokyo, Japan. ${ }^{4}$ Department of Respiratory Medicine, Nagasaki University Graduate School of Biomedical Sciences, Nagasaki, Japan.

Received: 12 May 2020 Accepted: 8 July 2020

Published online: 16 July 2020

\section{References}

1. Sperling O. Renal hypouricemia: classification, tubular defect and clinical consequences. Contrib Nephrol. 1992;100:1-14.

2. Ohta T, Sakano T, Igarashi T, Itami N, Ogawa T, ARF Associated with Renal Hypouricemia Research Group. Exercise-induced acute renal failure associated with renal hypouricaemia: results of a questionnairebased survey in Japan. Nephrol Dial Transplant. 2004. https://doi.org/10. 1093/ndt/gfh094.

3. Nishizaki N, Fujinaga S, Hirano D, Kanai H, Kaya H, Ohtomo $Y$, et al. Hereditary renal hypouricemia: a cause of calcium oxalate urolithiasis in a young female. Clin Nephrol. 2012. https://doi.org/10.5414/ CN106949.
4. Enomoto A, Kimura H, Chairoungdua A, Shigeta $Y$, Jutabha $P$, Cha SH, et al. Molecular identification of a renal urate anion exchanger that regulates blood urate levels. Nature. 2002. https://doi.org/10.1038/ nature742.

5. Hosoyamada M, Ichida K, Enomoto A, Hosoya T, Endou H. Function and localization of urate transporter 1 in mouse kidney. J Am Soc Nephrol. 2004; 15:261-8. https://doi.org/10.1097/01.asn.0000107560.80107.19.

6. Ichida K, Hosoyamada M, Hisatome I, Enomoto A, Hikita M, Endou H, et al. Clinical and molecular analysis of patients with renal Hypouricemia in Japan-influence of URAT1 gene on urinary Urate excretion. J Am Soc Nephrol. 2004;15:164-73.

7. Yamamoto I, Yamamoto H, Ichida K, Mitome J, Tanno Y, Katoh N, et al. Successful living-related kidney transplantation in hereditary renal hypouricaemia. Nephrol Dial Transplant. 2006;21:2041.

8. Okabayashi Y, Yamamoto I, Komatsuzaki Y, Niikura T, Yamakawa T, Katsumata $\mathrm{H}$, et al. Rare case of nephrocalcinosis in the distal tubules caused by hereditary renal hypouricaemia 3 months after kidney transplantation. Nephrology. 2016;21:67-71.

9. Varga Z, Gaspert A, Behnke S, von Teichman A, Fritzsche F, Fehr T. Tubular and endothelial chimerism in renal allografts using fluorescence and chromogenic in situ hybridization (FISH, CISH) technology. Pathol Int. 2012; 62:254-63.

10. Mori T, Hosomichi K, Chiga M, Mandai S, Nakaoka H, Sohara E, et al. Comprehensive genetic testing approach for major inherited kidney diseases, using next-generation sequencing with a custom panel. Clin Exp Nephrol. 2017;21:63-75. https://doi.org/10.1007/s10157-0161252-1.

11. Richards S, Aziz N, Bale S, Bick D, Das S, Gastier-Foster J, et al. Standards and guidelines for the interpretation of sequence variants: a joint consensus recommendation of the American College of Medical Genetics and Genomics and the Association for Molecular Pathology. Genet Med. 2015; 17:405-24.

12. Erley CMM, Hirschberg RR, Hoefer W, Schaefer K. Acute renal failure due to uric acid nephropathy in a patient with renal hypouricemia. Klin Wochenschr. 1989;67:308-12.

13. Greene ML, Marcus R, Aurbach GD, Kazam ES, Seegmiller JE. Hypouricemia due to isolated renal tubular defect. Dalmatian dog mutation in man. Am J Med. 1972. https://doi.org/10.1016/0002-9343(72)90181-7.

14. Iwai N, Mino Y, Hosoyamada M, Tago N, Kokubo Y, Endou H. A high prevalence of renal hypouricemia caused by inactive SLC22A12 in Japanese. Kidney Int. 2004;66:935-44.

15. Zhou Z, Ma L, Zhou J, Song Z, Zhang J, Wang K, et al. Renal hypouricemia caused by novel compound heterozygous mutations in the SLC22A12 gene: a case report with literature review. BMC Med Genet. 2018. https:// doi.org/10.1186/s12881-018-0595-8.

16. Tasic V, Hynes AM, Kitamura K, Cheong HI, Lozanovski VJ, Gucev Z, et al. Clinical and functional characterization of URAT1 variants. PLoS One. 2011;6(12):e28641

17. Ichida K, Hosoyamada M, Kamatani N, Kamitsuji S, Hisatome I, Shibasaki T, et al. Age and origin of the G774A mutation in SLC22A12 causing renal hypouricemia in Japanese. Clin Genet. 2008; $74: 243-51$

18. Sugihara S, Hisatome I, Kuwabara M, Niwa K, Maharani N, Kato M, et al. Depletion of uric acid due to SLC22A12 (URAT1) loss-of-function mutation causes endothelial dysfunction in hypouricemia. Circ J. 2015; 79:1125-32.

19. Dinour D, Bahn A, Ganon L, Ron R, Geifman-Holtzman O, Knecht A, et al. URAT1 mutations cause renal hypouricemia type 1 in Iraqi Jews. Nephrol Dial Transplant. 2011. https://doi.org/10.1093/ndt/gfq722.

20. Jeannin G, Chiarelli N, Gaggiotti M, Ritelli M, Maiorca P, Quinzani S, et al. Recurrent exercise-induced acute renal failure in a young Pakistani man with severe renal hypouricemia and SLC2A9 compound heterozygosity. BMC Med Genet. 2014. https://doi.org/10.1186/1471-2350-15-3.

21. Ohtsuka Y, Zaitsu M, Ichida K, Isomura N, Tsuji K, Sato T, et al. Human uric acid transporter 1 gene analysis in familial renal hypo-uricemia associated with exercise-induced acute renal failure. Pediatr Int. 2007. https://doi.org/ 10.1111/j.1442-200X.2007.02337.X.

22. Kaito H, Ishimori S, Nozu K, Shima Y, Nakanishi K, Yoshikawa N, et al. Molecular background of urate transporter genes in patients with exerciseinduced acute kidney injury. Am J Nephrol. 2013. https://doi.org/10.1159/ 000355430. 
23. Hisatome I, Tanaka Y, Kotake H, Kosaka H, Hirata N, Fujimoto Y, et al. Renal hypouricemia due to enhanced tubular secretion of urate associated with urolithiasis: successful treatment of urolithiasis by alkalization of urine $\mathrm{K}+, \mathrm{Na}(+)$-citrate. Nephron. 1993. https://doi.org/10. $1159 / 000187567$.

24. Yeun JY, Hasbargen JA. Renal hypouricemia: prevention of exercise-induced acute renal failure and a review of the literature. Am J Kidney Dis. 1995. https://doi.org/10.1016/0272-6386(95)90579-0.

\section{Publisher's Note}

Springer Nature remains neutral with regard to jurisdictional claims in published maps and institutional affiliations.

Ready to submit your research? Choose BMC and benefit from:

- fast, convenient online submission

- thorough peer review by experienced researchers in your field

- rapid publication on acceptance

- support for research data, including large and complex data types

- gold Open Access which fosters wider collaboration and increased citations

- maximum visibility for your research: over $100 \mathrm{M}$ website views per year

At $\mathrm{BMC}$, research is always in progress.

Learn more biomedcentral.com/submissions 